\title{
Mediação e Conciliação Judicial - A Importância da Capacitação e de seus Desafios ${ }^{1}$
}

\section{Court Connected Mediation and Conciliation - The Importance of Training and its Challenges}

\author{
Lilia Maia de Morais Sales \\ Universidade de Fortaleza (Unifor), Fortaleza, CE, Brasil
}

\section{Emmanuela Carvalho Cipriano Chaves}

Universidade de Fortaleza (Unifor), Fortaleza, CE, Brasil

\begin{abstract}
Resumo: Neste trabalho pretende-se analisar de que forma o Conselho Nacional de Justiça, que instituiu a Política Nacional de tratamento adequado dos conflitos de interesses, por meio da Resolução n. 125, de 29 de novembro de 2010 , tem conduzido as capacitações para conciliadores e mediadores judiciais. Para tanto, são analisados os desafios e as transformações após a Emenda n.1, de 23 de janeiro de 2013. Para subsidiar este estudo, foram realizados levantamento bibliográfico, análise de documentos e depoimentos e narrativas dos sujeitos interlocutores da pesquisa. $\mathrm{O}$ estudo revelou que essa Política Nacional precisa ser ampla, com estabelecimentos de parcerias por todo o Brasil, estimulando o desenvolvimento de treinamentos descentralizados e adequados às realidades de cada estado, contribuindo para a construção de uma cultura de excelência na capacitação de mediadores e conciliadores judiciais.
\end{abstract}

Palavras-chave: Conselho Nacional de Justiça. Conciliação. Mediação.
Abstract: The National Council of Justice (CNJ) in Brazil established, since November 2010, though 125 Resolution, the National Policy for conflict resolution mechanisms. This document pointed as very important topic, as well as designed, the trainings for judicial conciliators and mediators. In January, 2013, CNJ voted Amendment $n$. 1 which changed some principals on the 125 Resolution. This study aims to analyze these changes, challenges and transformations around training issues. Literature survey, document analysis, testimonies and narratives were conducted. The study showed that the National Policy needs to be broad enough so that reaches all states of Brazil, needs to establish many partnerships through out Brazil, stimulating decentralized and adequate to local reality trainings, making and effective contribution to excellence in judicial conciliators and mediators education.

Keywords: National Council of Justice. Conciliation. Mediation.

1 Recebido em: 14/7/2014

Revisado em: 26/8/2014

Aprovado em: 17/9/2014 


\section{Introdução}

A capacitação de mediadores e conciliadores, no Brasil, representa um ponto fundamental para a adequada implementação desses mecanismos de solução de conflitos de forma eficiente e competente. A Resolução n. 125 do Conselho Nacional de Justiça que, em novembro de 2010, instituiu a criação de núcleos e centros de solução de conflitos em todos os tribunais brasileiros, dispôs em seus artigos $9^{\circ}$ e 12 sobre o treinamento, a capacitação e a reciclagem dos envolvidos no processo de implementação dessa prática - mediação judicial - passando assim a entender a capacitação como critério para a atuação judicial de mediadores e conciliadores.

A partir dessa exigência, consolidou-se a busca pela qualidade dos serviços e a qualificação técnica da equipe envolvida na implementação dos núcleos, especialmente no que se refere às diferenças conceituais e práticas entre a mediação e a conciliação e a preparação dos operadores do Direito para atuar de forma consensual e não mais exclusivamente litigiosa. Lagrasta Neto (2008, p. 11) reflete sobre essa preocupação:

Se não houver mudança de estratégia na solução de conflitos, com intensa utilização de meios alternativos, previsto o engajamento de todos os lidadores do Direito, incluídos os servidores da Justiça, e o treinamento dos estudantes, desde os bancos acadêmicos, dificilmente se conseguirá alcançar o objetivo de amplo e irrestrito acesso a uma ordem jurídica justa, que nos encaminhe à mudança de mentalidade.

A capacitação adequada também auxilia corrigir o equívoco de que mediar ou conciliar é produzir acordo e que seu objetivo maior seria desafogar as vias judiciais. O Poder Judiciário, nas tratativas iniciais de implementação ou fortalecimento das práticas de mediação e de conciliação, tem expressado seu foco em número de acordos, o que pode ser desastroso em termos de eficácia e qualidade dessa prática. Para Souza Neto $(2000$, p. 64), “[...] o acordo iníquo é uma violação à dignidade do Judiciário [...] de prestigiar o injusto, criando verdadeira contradição filosófica-existencial no que pertine à finalidade precípua dos profissionais do Direito". 
Deve-se, assim, investir na capacitação de qualidade para que se compreenda adequadamente os meios consensuais de solução de conflitos, seus objetivos, implementando e realizando-os corretamente, tendo como foco a solução adequada de conflitos, o fortalecimento dos vínculos individuais e coletivos, proporcionando um sentimento de justiça e paz.

\section{A Mediação e Conciliação - O Desafio da Formação Jurídica Tradicional}

Para a adequada inserção da prática dos meios consensuais de solução de conflitos fora ou no âmbito do Poder Judiciário, os cursos, além das técnicas em mediação e conciliação, devem discutir a nova abordagem do conflito, do Direito, da Justiça. O perfil do profissional do Direito, que trabalhará com a mediação e a conciliação, requer um profissional receptivo a transformações, à escuta ativa e à valorização do diálogo, perfil este que vai de encontro a uma formação jurídica conservadora ainda viva nas faculdades de Direito do País e, que conforme Nalini (2009, p. 30), não aceita transformações facilmente e ainda é muito resistente ao diálogo com outras ciências ou esferas do conhecimento.

Faz-se assim necessária uma mudança na formação jurídica, diminuindo a normatividade excessiva, estimulando a interdisciplinaridade. Cappelletti e Garth (1988, p. 8), explicam a importância da dessa mudança:

Nenhum aspecto de nossos sistemas jurídicos modernos é imune à crítica. Cada vez mais pergunta-se como, a que preço e em benefício de quem estes sistemas de fato funcionam. Essa indagação fundamental que já produz inquietação em muitos advogados, juízes e juristas torna-se tanto mais perturbadora, em razão da invasão sem precedentes dos tradicionais domínios do Direito, por sociólogos, antropólogos, economistas, cientistas políticos e psicólogos, entre outros. Não devemos, no entanto, resistir a nossos invasores; ao contrário, devemos respeitar seus enfoques e reagir a eles de forma criativa. Através da revelação do atual modo de funcionamento de nossos sistemas jurídicos, os críticos oriundos das outras ciências 
sociais podem, na realidade, ser nossos aliados na atua fase de uma longa batalha histórica - a luta pelo 'acesso à justiça' .

Santos (2007, p. 68) considera a formação jurídica uma das reformas centrais do sistema de justiça. $\mathrm{O}$ argumento da autoridade e o exercício do poder sempre estiveram presentes nos cursos de Direito, conforme Morais e Copetti (2005, p. 48):

Desde 1827, com a fundação da Academia de Direito de São Paulo, os cursos de direito tiveram seu papel relevante na formação dos atores jurídicos dos locais de exercício do poder. [...] Os cursos, desde então, restringiram-se a uma visão positivista-legalista do fenômeno jurídico, consolidando uma postura pedagógica marcada pela glosa dos textos legais, sem qualquer preocupação crítico-reflexiva. A formação normativa expressa, muitas vezes, por argumentos de autoridade, aliada às relações pautadas na medição de forças e no litígio, dificultam a democratização do acesso à Justiça e a participação efetiva do cidadão na condução da solução dos conflitos. O Direito escrito e formalizado da moderna sociedade burguês-capitalista alcança o apogeu com sua sistematização científica, representada pela Dogmática Jurídica. O paradigma da Dogmática Jurídica forja-se sobre proposições legais abstratas, impessoais e coercitivas, formuladas pelo monopólio de um poder público centralizado (o Estado), interpretadas e aplicadas por órgãos (Judiciário) e por funcionários (os juízes) [...] Embora a dogmática jurídica estatal se revele, teoricamente, resguardada pelo invólucro da cientificidade, competência, segurança, na prática intensifica-se a gradual perda de sua funcionalidade e de sua eficácia. (WOLKMER, 2001, p. 59)

Com essa formação ${ }^{2}$, os profissionais da área do Direito possuem dificuldades em compreender o novo cenário exigido pela sociedade e apresentado pelos meios adequados ou consensuais de solução de conflitos. Cenário este que apresenta o diálogo como principal ferramenta na solução do problema, que possui como base a cooperação, o ganha-ga-

2 Para um maior detalhamento sobre a crise do ensino jurídico no Brasil e as novas necessidades sociais, ver Santos (2007, p. 71) e Morais e Copetti (2005, p. 47). 
nha, a escuta-ativa, a participação ativa e poder de decisão das pessoas envolvidas. Há assim um choque de realidades. De um lado a formação normativa, autoritária, não dialogada, adversarial e litigiosa; de outro uma proposta que requer uma formação interdisciplinar, que fortalece as pessoas na solução do conflito, aposta no diálogo e que incentiva a cooperação e a ressignificação dos conflitos.

\section{A Conciliação e a Mediação - Uma Realidade no Brasil}

A Constituição Federal brasileira de 1988, em seu preâmbulo, expressa a sua fundamentação na harmonia social e comprometimento com a ordem interna e internacional, além de afirmar o compromisso com a solução pacífica das controvérsias. A conciliação e a mediação são albergadas por esse preâmbulo. A conciliação, no entanto, esteve presente no texto da Constituição Imperial de 1824 e ao longo dos anos foi sendo apresentada em leis infraconstitucionais ${ }^{3}$ com forte expressão. Apesar da

3 Além da previsão constitucional da conciliação nas constituições republicanas brasileiras algumas leis infraconstitucionais são destaques no Brasil. O Código de Processo Civil de 1973 dispôs de uma seção sobre conciliação. No CPC/2002, a sua previsão e valorização ficou clara quando em seu art. 125 , IV, permitiu ao juiz convocar, a qualquer tempo, as partes para tentar conciliar. O que é reafirmado nos termos dos artigos 331 (modificado pela Lei n. 8.952, de 1994, e pela Lei n. 10.444, de 2002), estabelecendo a audiência preliminar, no procedimento comum ordinário, momento em que haverá a tentativa de acordo. Além dos artigos acima citados, há o art. 447 e seguintes, que dispõem sobre o dever do juiz estimular a conciliação a qualquer tempo, na audiência de conciliação, no procedimento ordinário e no início da audiência de instrução e julgamento, além disso, o art. 269 prevê a extinção do processo por força da autocomposição e o art. 272 a adoção da conciliação em todos os procedimentos especiais. Vale salientar a importância do disposto no art. 277 do CPC, que dispõe sobre o conciliador ser pessoa distinta do juiz da causa, o que não pode significar que o juiz não terá nenhuma responsabilidade sobre o processo, mas que uma pessoa capacitada deve conduzir o momento da conciliação. Os Juizados Especiais criados em 1995 pela Lei n. 9.099, sucedendo e ampliando a abrangência dos Juizados de pequenas causas (1984 - que previa a conciliação). A conciliação está prevista no artigo 21 ao artigo 26, dando prioridade à tentativa de conciliar ou até mesmo de instituir um juízo arbitral, além disso, a mesma lei admite a conciliação e a transação penais. A conciliação também teve o seu espaço garantido em leis especiais, como na Consolidação das Leis Trabalhistas - CLT que traz expressamente a conciliação em seus artigos 846 e 850, em momentos distintos do processo, incentivando a composição amigável, dentre outras. No Brasil, desde a Lei 
robusta previsão constitucional e infraconstitucional da conciliação, não há menção a qualquer exigência para a capacitação do conciliador. Como observa Luchiari (2012, p. 69), não há nenhuma previsão para a formação desses conciliadores:

O que é importante notar é que, em todos os procedimentos, a Lei prevê a conciliação como mecanismo para a obtenção de acordo, considerando este como modalidade de extinção do processo com resolução do mérito, e praticada pelo próprio juiz, que pode ser auxiliado por conciliador. Porém, não há qualquer previsão de formação especial desses facilitadores e é evidente que a atividade conciliadora do juiz é limitada, recebendo sua objetividade exacerbada, muitas críticas.

A mediação de conflitos, por sua vez, apesar de não fortemente expressa em lei, ${ }^{4}$ ganhou destaque nacional com a Resolução n. 125, do

n. 9.958/00, também ocorre a conciliação privada, que trata das Comissões de Conciliação Prévia relacionadas com os Direitos Trabalhistas. Além disso, a conciliação extrajudicial também ganha ênfase na Lei do Juizado Especial que dispõe, em seu artigo 57, sobre a validade do acordo extrajudicial como título executivo judicial.

4 No Brasil, a discussão sobre a mediação de conflitos teve início mais ou menos nos anos 1980 iniciada com a vinda de profissionais de outros países, especialistas na área, que vieram ministrar palestras e despertaram o interesse de profissionais para o estudo do tema, tempo e, pouco tempo depois foram criadas instituições que difundiam a temática e capacitavam profissionais, como o Instituto de Mediação e Arbitragem do Brasil (IMAB), criado em 1994 e o Conselho Nacional das Instituições de Mediação e Arbitragem (CONIMA), dentre outras que na subseção seguinte serão comentadas. (ADOLFO, 2012, p. 4-5). O advento da Lei n 9.307/96, Lei da Arbitragem, com a previsão expressa da conciliação e a arbitragem e outras leis trabalhistas (Lei n. 10.101/00) e escolares (Lei n. 9.870/99) utilizaram o termo mediação de conflitos, mas que na prática ocorria uma forte confusão de conceitos. Confirma Braga Neto (2012, p. 13), todas elas favorecem a confusão entre os mecanismos, pois misturam as nomenclaturas mediação, negociação e arbitragem. Em 1998 foi apresentado o Projeto de Lei n. 4.837 de autoria da Deputada Zulaiê Cobra Ribeiro, que em 2003 foi fundido com o Anteprojeto de lei do Instituto Brasileiro de Direito Processual e Escola Nacional da Magistratura. Após vários questionamentos de profissionais e estudiosos da área da mediação, e após vários substitutivos, atualmente o Projeto de Lei de Mediação encontra-se sem previsão para votação. Em 29 de novembro de 2010, o Conselho Nacional de Justiça instituiu a Política Judiciária Nacional de tratamento adequado dos conflitos de interesses por meio da Resolução n. 125 - prevendo e regulando a mediação judicial de conflitos. 
$\mathrm{CNJ} / 2010$, que já previu claramente a exigência de capacitação. Um dos maiores problemas enfrentados na capacitação e na implementação desses mecanismos consensuais de solução de conflitos no Brasil é a confusão de conceitos e de suas práticas. Os mecanismos mais confundidos pelos praticantes são a conciliação e a mediação de conflitos.

\subsection{Conciliação - Conceito e Considerações}

A conciliação é um mecanismo autocompositivo de solução de conflitos, que pode ser extrajudicial ou judicial (a classificação indica o momento em que ela ocorre - antes ou durante o processo judicial) e que conta com a participação de um terceiro imparcial e capacitado, que orientado pelo diálogo entre as partes envolvidas escuta ativamente, conduz a discussão, a partir do apresentado passa, se for o caso, a sugerir soluções compatíveis com o interesse das partes ou, uma vez apresentada a solução pelas próprias pessoas, a conduzir essa solução para que ela realmente reflita o interesse das partes em conflito.

No ordenamento jurídico brasileiro, a conciliação vem sendo utilizada, amplamente no processo civil, na área familiar e especialmente, na Justiça do Trabalho e nos Juizados Especiais. A conciliação poderá oportunizar um acordo livre e responsável, portanto com maior possibilidade de cumprimento.

Com a maior discussão no Brasil sobre a implementação e eficiência dos meios consensuais de solução de conflitos, inicia-se claramente uma preocupação com a qualidade da conciliação. Para Tartuce (2012, p. 155), é importante ter atenção para o que (não) é conciliar: “A despeito da falta de informações e aprendizado sobre as técnicas consensuais, ao atuar em juízo os jurisdicionados e seus representantes são instados a cogitar sobre a autocomposição [...]”, mas será que apenas a pergunta, muitas vezes dita: Tem acordo? É suficiente? Não estará sendo desperdiçado um momento precioso por falta de profissionais capacitados? Luchiari (2012, p. 15) chama atenção para a preocupante falta de capacitação de conciliadores: 
[...] deve-se diferenciar a conciliação, técnica não contenciosa de resolução de disputas, da conciliação levada a efeito nas audiências previstas no procedimento judicial com essa designação, pois neste último caso, em geral, os profissionais que a aplicam não tem formação em conciliação.

Para Vezzulla (2001, p. 83), o conciliador capacitado, que se utiliza da técnica da escuta ativa, consegue encontrar pontos convergentes que por serem melhores de discutir abrem espaço para concessões, então, a solução tende a ocorrer com maior facilidade e rapidez.

Ressalta-se assim a importância da capacitação de conciliadores para que a sua prática ocorra adequadamente sem que haja prejuízos ao processo e descrédito do Poder Judiciário. Um acordo consciente tem maior possibilidade de ser cumprido, e o espaço aberto para a conciliação deve ser aproveitado ao máximo para que a possibilidade de composição seja efetiva.

O conciliador assim deve estar apto para saber que a conciliação diferencia-se da mediação e que é mais adequada quando os conflitos são objetivos/patrimoniais, em que, preferencialmente não existam vínculos afetivos/familiares entre as partes, não sendo necessário um aprofundamento maior na discussão.

Nas palavras de Vezzulla (2001, p. 16), a conciliação exige um profissional que conheça técnicas, seja imparcial e pratique a escuta ativa, já a mediação exige a participação ativa dos mediados e deve ter a frente um mediador conhecedor de técnicas que facilitem a busca de opções para uma melhor solução (VEZZULLA, 2001, p. 24), sendo essencial que o conciliador e o mediador façam um trabalho de investigação, na conciliação mais superficial e na mediação mais aprofundado.

O conciliador, assim, na sua prática, participa mais ativamente da decisão podendo em alguns casos sugerir opções de acordo às partes, exatamente porque o tipo de conflito permite essa participação. Por suas peculiaridades, o objetivo desse mecanismo é o acordo satisfatório e consciente, aquele que seja exequível, minimizando o risco da continuidade ou acirramento do conflito. 


\subsection{Mediação de Conflitos - Conceito e Considerações}

A mediação é um mecanismo de solução de conflitos, no qual um terceiro imparcial e com capacitação adequada facilita a comunicação entre as partes, sem propor ou sugerir quanto ao mérito, possibilitando o diálogo participativo, efetivo e pacífico, permitindo-se a construção de uma solução satisfatória pelas próprias partes. A mediação possibilita, por meio de técnicas próprias, utilizadas pelo mediador, a identificação do conflito real vivenciado, suas possíveis soluções.

Os princípios da mediação de conflitos apresentam variações, mas alguns possuem um consenso entre os estudiosos: liberdade das partes, não competitividade, poder de decisão das partes, participação de terceiro imparcial, competência do mediador, informalidade do processo, confidencialidade e sigilo no processo.

Durante o processo de mediação o respeito aos princípios é fundamental para a condução adequada e eficaz. As pessoas devem ser livres para escolher o processo de mediação e possuir o poder de decisão durante o processo. Para que o mediador facilite o diálogo é indispensável que ele seja imparcial e capacitado, devendo ser escolhido ou aceito pelas partes, permitindo que o processo seja conduzido com informalidade, sigilo e confidencialidade.

A mediação objetiva, por suas características, além da solução de conflitos, a manutenção e o restabelecimento de vínculos e a pacificação das relações individuais e coletivas. Conforme esse raciocínio, explica Vezzulla (2001, p. 24), o conflito é definido como "[...] querer assumir posições que entram em oposição aos desejos do outro, que envolve uma luta pelo poder e que sua expressão pode ser explícita ou oculta atrás de uma posição ou discurso encobridor". Na mediação, os conflitos passam por um processo que vai além da sua resolução e que promove a pacificação das relações sociais.

Para que essa pacificação seja facilitada, o mediador deve transmitir buscar a cooperação entre os envolvidos, transmitindo a segurança e tranquilidade aos mediados para que consigam sair do confronto, e pacientemente conduzi-las a uma postura de cooperação, onde a raiva, o 
ódio, a inveja, o ciúme e todos os sentimentos que encobrem a realidade, sejam minimizados. Para Santos (1988, p. 21): “A estrutura da mediação é a topografia de um espaço de mútua cedência e de ganho recíproco".

Enquanto as partes estão firmes em suas posições de confronto, não existe margem para acordos sensatos, apenas ocorre a discussão ineficaz do querer de cada parte, o que gera riscos para os relacionamentos (FISHER; URY; PATTON, 2005, p. 21-32), ao permanecer na posição trabalha-se o conflito na sua superficialidade e muitas vezes o que é resolvido é o conflito aparente, não gerando o real ganho recíproco, deixando passar uma oportunidade, em alguns casos única, de pacificar o conflito real.

A atenção que o mediador necessita durante o processo de mediação se dá assim, especialmente, em função da complexidade nos conflitos humanos. Muitas vezes, os conflitos falados, expostos não são os conflitos que causam efetivamente a dor e a infelicidade. É comum a expressão dos conflitos aparentes, mas que não refletem o que verdadeiramente está causando angústia, insatisfação, intranquilidade ou outro sentimento que provoque mal-estar. Caso não haja um aprofundamento da discussão (especialmente em casos de relação continuada ou com sentimentos afetivos envolvidos) e não se consiga chegar ao conflito real, corre o risco de ser agravado e não solucionado. Pela complexidade do conflito, a mediação exige a exploração do problema e o aprofundamento sobre suas causas.

Para que ocorra esse diálogo, participativo e verdadeiro, é necessário que o mediador auxilie os mediados a chegarem à raiz do conflito. Warat (2001, p. 32) fala de mediação como um instituto que vai até o fundo de nossos mal-estares, encontrando assim a raiz geradora de um permanente estado de conflito conosco e com os outros de nosso convívio, proporcionando um reencontro que transforma.

Warat (2001, p. 89) completa dizendo que a mediação trabalha fundamentalmente os não ditos do sentido, pois são eles que revelam os detalhes do conflito. Esses detalhes devem ser percebidos pelo mediador e explorados para possibilitar o aprofundamento, facilitando para que os mediados saiam das posições, para os reais interesses e valores. Esse caminho que os mediados devem percorrer para a compreensão e pacifica- 
ção do conflito será efetivo, se facilitado por mediadores competentes, éticos e vocacionados.

Alguns aspectos são muito importantes para o êxito da implementação da mediação, dentre eles ressaltam-se dois: a capacitação (qualidades extrínsecas) do mediador e o perfil desse profissional (qualidades intrínsecas).

A capacitação está relacionada diretamente ao conhecimento sobre o processo de mediação, da pré-mediação, ${ }^{5}$ sessão de cáucus, ${ }^{6}$ diferenças conceituais e práticas dos vários meios consensuais de solução de conflitos, suas fases, seus princípios, seus objetivos e técnicas utilizadas (escuta ativa, ${ }^{7}$ a observação das expressões, as perguntas abertas, ${ }^{8}$ paráfrase, ${ }^{9}$ as anotações $\left.{ }^{10}\right)$. Essa capacitação deve ser contínua e cada vez mais profunda para que o mediador esteja em constante aperfeiçoamento.

5 Momento prévio à mediação, utilizado para mitigar o caráter adversarial tão comum entre pessoas em conflito, fruto da representação do litígio arraigada à cultura do povo brasileiro; explicar a responsabilidade das partes pelo processo de mediação e que o mediador não decide, não sugere soluções e não oferece assessoramento legal; esclarecer sobre o trabalho cooperativo entre as partes, a necessidade do respeito mútuo e a exigência da escuta atenta ao que cada um deseja; esclarecer sobre o processo de mediação, sobre a função do mediador e sobre suas peculiaridades.

6 Sessões de diálogo em separado das partes com o mediador. Esses momentos podem ser sugeridos pelo mediador quando ele sente que uma das partes não deseja falar sobre determinados assuntos na presença da outra pessoa. Assim, com a concordância de ambas as partes o mediador conversará separadamente com cada pessoal envolvida no conflito.

7 Conforme Vezzulla (2001, p. 31), na mediação a escuta atenta dos mediados é a chave que abre as portas para conhecer e reconhecer o que realmente interessa e daí chegar a acordos que sejam por eles respeitados.

8 Como a mediação estimula o aprofundamento dos conflitos e a participação das partes, que se responsabilizam pela construção do diálogo, o mediador se utiliza de perguntas abertas como meio de fazer os mediados refletirem e encontrarem respostas que estão dentro de cada um deles, evitando o pré-julgamento e a parcialidade. As perguntas abertas não induzem e nem direcionam, mas estimulam os mediados a uma introspecção, na busca por respostas, que revela soluções mais sensatas, pois são trazidas por quem de fato está vivenciando o conflito.

9 A utilização de paráfrase auxilia a identificação entre o que foi falado pelas partes e o que foi expresso pelo mediador. A paráfrase ajuda o mediador a garantir que tudo o que foi falado realmente foi compreendido pelas partes do conflito.

10 A anotação é fundamental para que o mediador destaque pontos que considere importantes que precisam ser lembrados ou bem esclarecidos. As pessoas, ao falar na 
Vezzulla (2001, p. 47-48) explica a atuação do mediador a partir do que ele não deve ser: não é juiz, também não é um negociador que toma parte na negociação, com interesse direto no resultado e nem é um árbitro que emite um laudo ou decide. O mediador está preocupado especialmente com o relacionamento entre as partes e em fazer com que elas descubram os seus reais interesses. Ele é um terceiro que facilita sem decidir, pois ninguém sabe mais do que elas próprias para decidir sobre si mesmas.

O perfil do mediador, por sua vez, faz referência às características intrínsecas como a aptidão para auxiliar e estimular a cooperação e o ganha-ganha, a facilidade de ouvir, realizar a escuta ativa e facilitar o diálogo, aberto para a interdisciplinaridade, humilde para não intervir ou decidir, criativo para auxiliar as pessoas no encontro dos pontos convergentes na condução de uma solução satisfatória.

Warat (2001, p. 25) discorre sobre "o momento certo" que em grego quer dizer, kairos, um acontecimento único onde a vida e a oportunidade encontram-se e produzem um acontecimento único, é o modo de encontrar-se consigo mesmo. A mediação é esse momento onde é oportunizado aos mediados um encontro, consigo mesmo e com o outro que, se aproveitado da melhor maneira, transforma as pessoas.

A implementação da mediação e dos outros meios consensuais junto ao Poder Judiciário requer uma atenção ainda maior, pois eles se apresentam com uma lógica diversa do tradicional processo judicial. Enquanto a atuação tradicional junto ao Poder Judiciário ressalta o formalismo, a excessiva normatividade, o caráter adversarial do litígio, o perde ganha, o pouco diálogo, o poder de decisão do juiz a atuação requerida na prática dos meios consensuais ressalta o diálogo, a cooperação, o ganhaganha, a escuta-ativa, a empatia ${ }^{11}$ a convergência, a interdisciplinaridade.

sessão de mediação, trazem muitas informações que dificilmente seriam lembradas pelo mediador caso ele não utilizasse do recurso das anotações. Resumir é importante para organizar as ideias em cada fase da mediação. $\mathrm{O}$ mediador deve procurar resumir o que foi dito pelas partes, utilizando-se de palavras ditas e especialmente as repetidas pelas pessoas. Sempre deve perguntar se está correto ao resumir. Se o que ele disse, reflete o que as partes discutiram.

11 Empatia: colocar-se no lugar do outro. A mediação de conflitos estimula a empatia, instigando às partes a perceberem o outro pelo olho do outro. Permite assim a 
Conscientes de que a implementação da Resolução n. 125 do Conselho Nacional de Justiça - Política Nacional de tratamento adequado dos conflitos de interesses - encontraria dificuldades na formação jurídica dogmática, seus idealizadores tornaram obrigatória a capacitação de mediadores e conciliadores, exigindo uma grade mínima para os cursos de formação.

Nessa perspectiva, deve-se compreender a Resolução n. 125, do $\mathrm{CNJ}$, em dimensão macro que envolve desde a conscientização da população e dos profissionais do Direito e possibilidade de incentivo ao debate sobre transformação do ensino jurídico no Brasil como a elaboração de cursos de capacitação atuais e condizentes com esta nova realidade.

\section{Os Cursos de Capacitação e os Desafios Advindos da Imple- mentação da Resolução n. 125 do CNJ e a Emenda n.1, de 23 de janeiro de 2013: o relato de uma experiência}

Com a crescente prática da mediação e da conciliação em todo o país - demonstrando a viabilidade destes mecanismos para atingir a pacificação social, por meio da solução e prevenção de conflitos - e na busca pelo acesso à justiça como uma ordem jurídica justa, o Conselho Nacional de Justiça, atento aos resultados obtidos a partir destas práticas, instituiu uma Política Pública que objetiva organizar e uniformizar os serviços junto ao Poder Judiciário.

Dessa forma, na busca por possibilitar aos profissionais que lidam com a área do Direito o contato com estas novas abordagens e a ampliação do seu campo de visão, a Resolução n. 125/2010 do CNJ, em seu artigo $2^{\circ}$, enfatiza a relevância da adequada formação e treinamento de servidores, conciliadores e mediadores, com vistas à boa qualidade dos serviços, nos núcleos e centros. Observando-se inclusive em seu artigo $9^{\circ}, \S 2^{\circ}$, a importância de um profissional capacitado também para a triagem e encaminhamento adequado dos casos, demonstrando a preocupa-

ressignificação de valores. Importa aos mediadores, sempre que possível, buscar fazer com que os mediados consigam "ver o mundo pelo olho do outro", na busca da real compreensão do sentimento. 
ção com a formação dos profissionais que irão trabalhar diretamente com a prática da mediação judicial e da conciliação judicial.

\subsection{Capacitação nos Moldes da Resolução n. 125}

A Resolução n. 125 do Conselho Nacional de Justiça requereu assim a capacitação como requisito para a atuação de mediadores e de conciliadores junto aos núcleos criados nos tribunais de justiça do País e apresentou, em seu anexo I, as diretrizes para essa capacitação. A formação mínima seria composta por módulos sucessivos e complementares:

O Módulo I, com 12 horas/aula, denominado 'Introdução aos Meios Alternativos de Solução de Conflitos' versando sobre os diferentes meios não adversariais de solução de conflitos, com noções básicas sobre o conflito e a comunicação, disciplina normativa sobre o tema, experiências nacionais e internacionais, assegurando a compreensão dos objetivos da política pública de tratamento adequado de conflitos.

O Módulo II, com 16 horas/aula, denominado 'Conciliação e suas Técnicas' se propôs a habilitar os facilitadores na utilização de técnicas autocompositivas de solução de conflitos, com enfoque na negociação e conciliação, trazendo padrões de comportamento ético e posturas exigidas no relacionamento com partes e diferentes profissionais envolvidos.

O Módulo III, com 16 horas/aula, denominado 'Mediação e suas Técnicas' se propôs a habilitar os facilitadores na utilização de técnicas autocompositivas de solução de conflitos, com enfoque na mediação, identificando as diferentes Escolas, a multidisciplinaridade, as formas de sua aplicação, com destaque para a mediação judicial.

Os Módulos II e III seriam necessariamente seguidos de estágio supervisionado. Para o Módulo II a carga horária será de 12 horas e para o Módulo III será de 24 horas. Os certificados de capacitação apenas seriam emitidos após a conclusão do estágio supervisionado. Em relação aos servidores, o módulo I deveria ser complementado por módulo específico, destinado a detalhar o 'modus 
operandi' do CRD, os procedimentos administrativos, de orientação ao público e de encaminhamento a entidades parceiras e outros órgãos públicos.

Finalmente, desenvolveu-se Módulo específico para os magistrados, com o objetivo de integrá-los à Política Pública de tratamento adequado de conflitos, apresentando os principais métodos alternativos de solução de conflitos e suas aplicações, bem como detalhando o funcionamento dos CRDs. (Anexo I da Resolução $\mathrm{n}$. 125 do Conselho Nacional de Justiça, 29 de novembro de 2010, grifos nossos)

Em seus artigos $4^{\circ}, 5^{\circ}$ e $6^{\circ}$, a referida resolução dispôs que o programa de promoção de incentivo à autocomposição de litígios e a pacificação social por meio da conciliação e da mediação seria implementado com a participação de rede desenvolvida pelo Conselho Nacional Justiça e deveria buscar a cooperação dos órgãos públicos competentes e das instituições públicas e privadas da área de ensino, para a criação de disciplinas que propiciassem o surgimento da cultura da solução pacífica dos conflitos.

Buscou assegurar ainda que nas Escolas da Magistratura, tanto nos cursos de iniciação funcional e como nos cursos de aperfeiçoamento, houvesse módulo destinado aos métodos consensuais de solução de conflitos, além de estabelecerem interlocução com a Ordem dos Advogados do Brasil, Defensorias Públicas, Procuradorias e Ministério Público, estimulando a participação destes nos Centros Judiciários de Solução de Conflitos, Cidadania e valorizando a atuação na prevenção dos litígios.

Assim, ainda que o Tribunal de Justiça disponibilizasse diretamente os cursos de capacitação de conciliadores e mediadores, seria necessário que o 'Núcleo', por meio de parcerias, habilitasse as entidades públicas e/ ou privadas aptas a realizar a capacitação, a fim de que os certificados por elas emitidos sejam reconhecidos para a inscrição e inclusão de conciliadores e mediadores no cadastro do Tribunal. 
Para isso o núcleo deveria exigir dessas instituições: 1) experiência na atuação na capacitação de conciliadores e mediadores ou na área de ensino; 2) a apresentação de programa de aulas adequado ao conteúdo programático e carga horária, mínimos, previstos no Anexo I; 3) corpo docente suficiente para atender à demanda, com a qualificação adequada (pelo menos, pós-graduação); 4) e, se houver a cobrança de taxa de inscrição, a apresentação de justificativa do valor cobrado, através de quadro de despesas que inclua a remuneração dos professores e o pagamento dos impostos devidos.

O credenciamento das instituições aptas a realizar os cursos de capacitação em mediação e conciliação de conflitos junto aos Núcleos apresentou-se como adequada e de suma importância por vários motivos: 1) reconhecia a existência de instituições no Brasil que trabalhavam com o ensino e com a prática da mediação há décadas e por isso legitimas para capacitar mediadores e conciliadores judiciais (como o caso do IMAB, ${ }^{12}$ Instituto de Mediação e Arbitragem do Brasil, que capacita profissionais desde 1994, o Conselho Nacional das Instituições de Mediação e Arbitragem, CONIMA, ${ }^{13}$ desde 1997, como várias universidades brasileiras públicas e privadas espalhadas de norte a sul do País); 2) estimulava a pluralidade de instituições dedicadas ao tema, criando uma rede nacional de instituições aptas a capacitar em mediação e conciliação, fortalecendo essa prática no Brasil; 3) respeitava as particularidades de cada estado, uma vez que os cursos, respeitando, as regras estabelecidas na resolução, poderiam ser enriquecidas com discussões sobre aspectos locais muitas vezes definidores da aceitação e eficácia da nova prática.

A busca por parcerias, expressa na Resolução n. 125 demonstra que na sua elaboração respeitou-se o trabalho ativo de instituições brasileiras que durante os últimos 20 anos dedicaram-se ao tema, como as citadas anteriormente, incluindo aqui ainda, o Fórum Nacional de Me-

12 Para saber mais sobre o IMAB: Disponível em: <http://www.imab-br.net/pt/index. html>. Acesso em: 29 maio 2013.

13 Para saber mais sobre o CONIMA: Disponível em: <http://www.conima.org.br/> . Acesso em: 29 maio 2013. 
diação, o FONAME; ${ }^{14}$ ações da Secretaria da Reforma do Poder Judiciário com a Justiça Comunitária. ${ }^{15}$

\subsection{A Emenda n.1, de 23 de Janeiro de 2013}

Em Janeiro de 2013, o anexo I da Resolução n. 125 do CNJ foi expressivamente alterado. Mesmo diante da necessidade dos núcleos criarem e manterem um cadastro único de conciliadores e mediadores, por meio da promoção de capacitação, treinamento e atualização permanente de magistrados, servidores, conciliadores e mediadores com a realização de cursos de mediação e conciliação, ou seja, de ter profissionais aptos para desempenhar as funções com qualidade e em tempo hábil, a Emenda n.1, de 23 de janeiro de 2013, passou a requerer que a formação acontecesse exclusivamente por meio dos cursos de capacitação elaborados pelo Comitê Gestor do Movimento pela Conciliação, do Conselho Nacional de Justiça, sob a justificativa de que os cursos ministrados anteriormente com base nos conteúdos programáticos exigidos pela Resolução n. 125 estavam sendo implantados sem o módulo de simulados e estágios supervisionados necessários a adequada formação de mediadores e conciliadores.

A partir dessa alteração, restringiram-se as parcerias e a participação de instituições brasileiras na condução da capacitação, pois os cursos passaram a ter que seguir módulos pré-definidos e disponíveis no Portal

14 Que é formado por instituições que se dedicam ao aperfeiçoamento, a divulgação e a prática da mediação de conflitos, e que dispõe em seu regulamento interno, artigo $2^{\circ}$, III, que, dentre os seus objetivos, está a preocupação com a formulação e a definição de critérios ou indicadores destinados a constituir parâmetros, mínimos e/ou ótimos a serem observados na capacitação, na formação, na sensibilização, na qualificação de profissionais, na orientação quanto a preceitos e procedimentos éticos que devem ser observados pelos profissionais, voluntários, servidores e estudiosos que atuem com os meios de solução pacífica de conflitos, deste modo, já se interessa pela condução competente destes mecanismos. Para saber mais sobre o FONAME: Disponível em: $<$ http://www.foname.com.br/quem-somos/>. Acesso em: $1^{\mathrm{o}}$ jun. 2013.

15 Foi criada, em 2003, a Secretaria de Reforma do Poder Judiciário do Ministério de Justiça, objetivando o aperfeiçoamento do Poder Judiciário. E, em dez anos de criação, dentre as ações que se voltaram para a democratização do acesso à justiça, pode ser citada a implementação de Núcleos de Justiça Comunitária, que capacitaram cidadãos em técnicas de mediação de conflitos, em 15 estados brasileiros. 
da Conciliação do Ministério da Justiça. Além disso, passou a haver a exigência dos treinamentos serem conduzidos inicialmente pelo Ministério da Justiça, e posteriormente apenas por instrutores certificados e autorizados (que previamente atenderam ao curso ministrado pelo Ministério da Justiça) pelos Núcleos Permanentes de Métodos Consensuais de Solução de Conflitos.

Essa metodologia, apesar de estar formalmente bem estruturada, com a realização de vários cursos, ${ }^{16}$ (tendo em vista a justificativa lógica de um curso único em que instrutores seriam capacitados - sem custos para os tribunais - e teriam que, voluntariamente, ministrar cinco cursos -

16 Em setembro de 2011, o Conselho Nacional de Justiça, disponibilizou duas turmas do primeiro curso de formação para instrutores em Brasília. Logo, foram estipulados alguns critérios para selecionar os participantes do curso, dentre os quais estão: ter cursado uma formação em mediação de conflitos com duração mínima de 32 horas, que deveria ter sido feito a mais de seis meses, e, além disso, mais de 50 horas de experiência prática. Também foi exigida a autorização do Núcleo do Tribunal de Justiça ao qual o servidor estivesse vinculado, pois este é quem deveria arcar com todas as despesas, além de se comprometer em manter o servidor em função que o possibilite multiplicar o seu conhecimento, sem o prejuízo das suas funções. Durante a seleção, o comitê responsável, verificava a experiência do candidato em docência, participações anteriores em treinamentos em mediação de conflitos e conciliação e o tempo de serviço público. Além disso, os participantes teriam que cumprir algumas exigências para conseguirem a certificação, dentre as quais, o comprometimento em multiplicar o seu conhecimento, no prazo de (dois) anos, em cinco turmas de cursos de capacitação conforme a Resolução n. 125, de 29 de novembro de 2010, no Núcleo do Tribunal ao qual está vinculado ou eventualmente em outro Tribunal. Todos estes dados constam do Regulamento de Inscrição do primeiro Curso de Formação para Instrutores em Mediação e Conciliação para a Justiça Estadual. A partir de então outros cursos de formação de Instrutores para a Justiça Estadual aconteceram: em abril de 2012, aconteceram duas turmas do II Curso de Formação de Instrutores em Conciliação e Mediação; em setembro e em outubro de 2012 e, duas turmas do III Curso de Formação de Instrutores em Conciliação e Mediação, ambos em Brasília, Distrito Federal; e em maio de 2013, o II Curso de Formação de Instrutores em Conciliação e Mediação, que aconteceu na Escola Paulista da Magistratura, em São Paulo/SP. Além disso, aconteceram o I Curso de Formação de Instrutores da Justiça Federal em Políticas Públicas em Conciliação e Mediação; e o I Curso de Formação de Instrutores da Justiça Estadual em Políticas Públicas em Conciliação e Mediação, que ocorreram em maio de 2012, também em Brasília - Distrito Federal, já com uma nova exigência, a de multiplicar o conhecimento em apenas um ano, a no mínimo cinco turmas. 
com o mesmo material didático do Ministério da Justiça - multiplicando o conhecimento), pela exclusividade na autoria da capacitação e material didático geral padronizado, reduziu a participação de instituições brasileiras importantes na área de mediação e a não contemplação nos cursos dos temas e situações peculiares de cada região e de cada cidade onde os núcleos são implantados.

Com essas medidas, as comunidades acadêmica e profissional que estudam, pesquisam e trabalham a mediação, há mais de duas décadas no Brasil, preocupados com a qualidade e centralização da capacitação em mediação e ainda com a impossibilidade de parcerias efetivas, passaram a questionar: 1) Será que a mediação de conflitos e a conciliação são fortalecidas quando devem seguir estritamente e exclusivamente a modelos de cursos generalistas/padronizados e que não atentam as necessidades de cada região? 2) Será que a centralização da capacitação para a mediação judicial pelo CNJ não dificulta e engessa o exercício da mediação judicial e a qualidade o exercício dos mecanismos consensuais de solução de conflitos fica comprometida? 3) Será que esta formação exclusiva não estaria sendo inadequada em função de sua generalidade e formalismo e até que ponto a qualificação estaria atingindo o escopo de formar pacificadores sociais, atentos à realidade concreta? 4) Será que impedir ou dificultar que os tribunais firmem parcerias para a capacitação de cursos é uma medida adequada quando a base conceitual e prática desses mecanismos é a cooperação? 5) Será que a limitação às parcerias não dificulta a implementação desses mecanismos? 6) Será que cursos customizados, desde que seguindo as diretrizes do CNJ, como orientava a Resolução n. 125 antes da Emenda n. 1, não seria mais eficaz? 7) Será que a disponibilidade de curso ofertado pelo comitê gestor do Conselho Nacional de Justiça (modelo disponível no Portal da Conciliação, atualmente vigente) como opção (e não como obrigatório) para capacitar mediadores e instrutores nos estados brasileiros, especialmente para aqueles estados nos quais os tribunais não conseguissem êxito com parcerias locais, não seria uma proposta mais agregadora e realmente focada em criar uma rede forte de mediação e conciliação no Brasil?

Diante do debate, em 5 de setembro a Portaria n. 1.920, de 4 de setembro de 2012, do Ministério da Justiça, que entrou em vigor na data da 
sua publicação, 5 de setembro de 2012, criou a Escola Nacional de Mediação e Conciliação (ENAM), também com a intenção de disponibilizar cursos de capacitação e especialização, presenciais e a distância.

No entanto, apesar da Escola Nacional de Mediação e Conciliação (ENAM) ter firmado um acordo de cooperação técnica com a Universidade de Brasília (UnB), a Secretaria de Reforma do Judiciário do Ministério da Justiça ainda será responsável pelo material didático, por professores, pelas diretrizes, além disso, supervisionará e financiará o projeto. Será que a ENAM possibilitará a formação de uma rede de parcerias?

\section{Conclusão}

O Conselho Nacional de Justiça, atento às necessidades de aprimoramento do processo judicial e do acesso à Justiça, instituiu a Resolução n. 125 , de 29 de novembro de 2010. Essa resolução implementou a Política Nacional de Tratamento Adequado dos Conflitos, requerendo a efetivação da mediação e a conciliação de conflitos no âmbito do Poder Judiciário, por meio de centros que oferecessem à população esses serviços de forma adequada e qualificada.

A capacitação dos profissionais responsáveis pela mediação e conciliação foi apontada pela referida Resolução como crucial ao êxito do projeto, sendo apresentada necessidade da capacitação, orientações gerais sobre os temas a serem abordados nos cursos, carga horária mínima e realização de parcerias com o intuito de fortalecer aos centros nos tribunais em todos os estados brasileiros.

Em janeiro de 2013, no entanto, a Emenda n.1 à Resolução 125, que passou a requerer que as capacitações acontecessem exclusivamente por meio dos cursos de capacitação elaborados pelo Comitê Gestor do Movimento pela Conciliação, do Conselho Nacional de Justiça, não mais permitindo as parcerias para elaboração de material didático ou realização de cursos. Essa centralização e generalização dos cursos geraram um intenso debate, acompanhado de questionamentos, nas comunidades acadêmica e profissional que estudam, pesquisam e trabalham a mediação há décadas. 
Ainda em 2013, no entanto, foi criada a Escola Nacional de Mediação e Conciliação (ENAM), com a parceria entre o Ministério da Justiça e a Universidade de Brasília (UnB) com o intuito. Fica o questionamento: será que a criação da ENAM aponta para o início da descentralização e valorização de parcerias?

O presente artigo aponta como sugestões para fortalecer a implementação da mediação de conflitos no Brasil, como o credenciamento pelo Conselho Nacional de Justiça das instituições aptas a capacitar profissionais mediadores e conciliadores (exemplo: universidades brasileiras e instituições com histórico em desenvolver capacitações) e, a contínua atualização dos programas de capacitação com vistas a uma adequação a realidade de cada Tribunal e região.

Os debates e discussões em torno das atividades desenvolvidas (discussões e capacitações) a partir da criação da Resolução n. 125 do Conselho Nacional de Justiça demonstram que, além fomentar o estudo e a prática da mediação, expressam o reconhecimento da existência da prática da mediação de conflitos muito anterior à elaboração da Resolução que deve ser respeitada e preservada para uma implementação desse mecanismo junto ao Poder judiciário de forma adequada, democrática e inclusiva.

\section{Referências}

BRAGA NETO, Adolfo. Breve história da mediação de conflitos no Brasil - Da iniciativa privada à política pública. In: BRAGA NETO, Adolfo; SALES, Lilia Maia de Morais. (Org.). Aspectos atuais sobre a mediação e outros métodos extras e judiciais de resolução de conflitos. Rio de Janeiro: GZ, 2012. p. 3-19.

CAPPELLETTI, Mauro; GARTH, Bryant. Acesso à justiça. Tradução de Ellen Gracie Northfleet. Porto Alegre: Fabris, 1988.

FISHER, Roger; URY, William; PATTON, Bruce. Como chegar ao sim: a negociação de acordos sem concessões. Tradução de Vera Ribeiro e Ana Luzia Borges. 2. ed. rev. e ampl. Rio de Janeiro: Imago, 2005. 
LAGRASTA NETO, Caetano. Mediação, conciliação e suas aplicações pelo tribunal de justiça de São Paulo. In: GRINOVER, Ada Pellegrini; WATANABE, Kazuo; LAGRASTA NETO, Caetano (Coord.). Mediação e gerenciamento do processo: revolução na prestação jurisdicional: guia prático para a instalação do setor de conciliação e mediação. São Paulo: Atlas, 2008. p. 11-17.

LUCHIARI, Valéria Ferioli Lagrasta. Mediação judicial: análise da realidade brasileira origem e evolução até a Resolução n. 125, do Conselho Nacional de Justiça. In: GRINOVER, Ada Pellegrini; WATANABE, Kazuo (Coord.). Rio de Janeiro: Forense, 2012. (Coleção ADRS)

MORAIS, José Luis Bolzan de; COPETTI, André. Ensino jurídico, transdisciplinaridade e estado democrático de direito: possibilidades e perspectivas para o estabelecimento de um novo paradigma. Revista do Instituto de Hermenêutica Jurídica, Porto Alegre, v.1, n.3, p. 45-82, 2005. NALINI, José Renato. Conselho Nacional de Justiça: um marco no poder judiciário. Revista Jurídica Consulex, São Paulo, ano XIIII, n. 310, p. 28-30, 15 dez. 2009.

SANTOS, Boaventura de Sousa. O discurso e o poder: ensaio sobre a sociologia da retórica jurídica. Porto Alegre: Sergio Antônio Fabris Editor, 1988.

SANTOS, Boaventura de Sousa. Para uma revolução democrática da justiça. São Paulo: Cortez, 2007. (Coleção questões da nossa época; v. 134)

SOUZA NETO, João Baptista de Melo e. Mediação em juízo: abordagem prática para obtenção de um acordo justo. São Paulo: Atlas, 2000.

TARTUCE, Fernanda. Conciliação em juízo: o que (não) é conciliar? In: SALLES, Carlos Alberto; LORENCINI, Marco Antônio Garcia Lopes; SILVA; Paulo Eduardo Alves da (Coord.). Negociação, mediação e arbitragem: curso básico para programas de graduação em Direito. Rio de Janeiro: Forense; São Paulo: Método, 2012. p. 149-178. 
VEZZULLA, Juan Carlos. Mediação: guia para usuários e profissionais. Florianópolis: Juan Carlos Vezzulla; Dominguez \& Dominguez, 2001.

VEZZULLA, Juan Carlos. Teoria e pratica da mediação. Curitiba: Instituto de Mediação e Arbitragem do Brasil, 2001.

WARAT, Luis Alberto. O ofício do mediador. Florianópolis: Habitus, 2001.

WOLKMER, Antônio Carlos. Pluralismo jurídico: fundamentos de uma nova cultura no Direito. 3. ed. São Paulo: Salfa Omega, 2001.

BRASIL. Conselho Nacional de Justiça. Resolução n. 125 do Conselho Nacional de Justiça. Dispõe sobre a Política Judiciária Nacional de tratamento adequado dos conflitos de interesses no âmbito do Poder Judiciário e dá outras providências. Disponível em: $<$ http://www.cnj. jus.br/atos-administrativos/atos-da-presidencia/323-resolucoes/12243resolucao-no-125-de-29-de-novembro-de-2010>. Acesso em: 15 nov. 2011.

BRASIL. Conselho Nacional de Justiça. Emenda n. 1, de 31 de janeiro de 2013. Altera os artigos $1^{\circ}, 2^{\circ}, 6^{\circ}, 7^{\circ}, 8^{\circ}, 9^{\circ}, 10,12,13,15,16,18$ e os Anexos I, II, III e IV da Resolução n. 125, 29 nov. 2010. Disponível em: $<$ http://aplicacao.tst.jus.br/dspace/bitstream/handle/1939/28620/2013_ emenda0001_res0125_2010_cnj.pdf?sequence=2>. Acesso em: $10 \mathrm{fev}$. 2013.

CONSELHO NACIONAL DAS INSTITUIÇÕES DE MEDIAÇÃO E ARBITRAGEM - CONIMA. [2013]. Disponível em: <http://www. conima.org.br/>. Acesso em: 29 maio 2013.

ESCOLA NACIONAL DE MEDIAÇÃO E CONCILIAÇÃO - ENAM. [2013]. Disponível em: <http://www.cead.unb.br/index.php/todas-asnoticias/307-enam-abre-inscricoes-para-curso-de-mediacao.html $>$. Acesso em: 26 jul. 2013.

FÓRUM NACIONAL DE MEDIAÇÃO - FONAME. Disponível em: $<$ http://www.foname.com.br/quem-somos/>. Acesso em: $1^{\text {o }}$ jun. 2013. 
INSTITUTO DE MEDIAÇÃO E ARBITRAGEM DO BRASIL - IMAB. [2013]. Disponível em: <http://www.imab-br.net/pt/index.html>. Acesso em: 29 maio 2013.

MEDIADORES e conciliadores serão capacitados para resolução extrajudicial de conflitos. [2014]. Disponível em: <http://www.brasil. gov.br/cidadania-e-justica/2012/10/escola-vai-formar-mediadores-econciliadores-para-resolucao-extrajudicial-de-conflitos $>$. Acesso em: 15 jan. 2014.

Lilia Maia de Morais Sales é Bolsista de Produtividade em Pesquisa-CNPq, Pós-doutora pela Universidade de Columbia (EUA), doutora em Direito pela Universidade Federal de Pernambuco, mestre e graduada em Direito pela Universidade Federal do Ceará. Possui formação em mediação de conflitos na Universidade de Harvard, junto ao Program on Negotiation (EUA). Professora titular da Universidade de Fortaleza no Programa de Pós-Graduação (Mestrado e Doutorado) em Direito Constitucional, Vice-Reitora de Pesquisa e PósGraduação da Universidade de Fortaleza, Membro do Conselho do Global Center de Columbia no Brasil e Membro do Conselho Superior da Fundação Cearense de Apoio ao Desenvolvimento Científico e Tecnológico (FUNCAP). Advogada e mediadora, coordena vários projetos de pesquisa na área de mediação de conflitos, além projetos que implementaram a mediação nas comunidades, na delegacia de polícia e em escolas públicas.

E-mail: 1ilia@unifor.br.

Endereço profissional: Av. Washinton Soares, 1321, Edson Queiroz, Fortaleza, CE, Brasil.

Emmanuela Carvalho Cipriano Chaves é Coordenadora do Curso de Especialização em Mediação de Conflitos da Universidade de Fortaleza. Professora do Curso de Direito da Universidade de Fortaleza (Unifor), Supervisora do Projeto de Mediação de Conflitos da FANOR. Membro do Grupo de Estudos e Pesquisas em Direitos Culturais da Universidade de Fortaleza. Mestre em Direito Constitucional pela Universidade de Fortaleza. Especialista em Processo Civil 
e Gestão do Processo pela Escola de Magistratura do Estado do Ceará ESMEC. Graduada em Direito pela Universidade de Fortaleza. Mediadora de Conflitos. Advogada. Atuou como professora de cursos de Formação para Mediadores e Conciliadores do Tribunal de Justiça do Estado do Ceará, da Defensoria Pública do Estado do Ceará e da Guarda Municipal de Fortaleza. Atuou como mediadora do Núcleo de Mediação de Conflitos no 30 Delegacia de Polícia Civil de Fortaleza. E-mail: emmanuelacarvalho1@unifor.br.

Endereço profissional: Av. Washinton Soares, 1321, Edson Queiroz, Fortaleza, CE, Brasil. 
